\title{
APARIENCIA Y REALIDAD EN LA RESPONSABILIDAD PATRIMONIAL DEL ESTADO JUEZ (LIMITADA VIGENCIA DEL ARTÍCULO $121 \mathrm{CE}$ )
}

\author{
LUÍS RODRÍGUEZ RAMOS \\ Catedrático de Derecho penal y abogado
}

\section{SUMARIO}

I. Introducción. II. Precedentes y desarrollo legislativo. III. Perversa interpretación jurisprudencial del derecho aplicable. IV. Derecho comparado. V. Propuestas interpretativas y de lege ferenda.

\section{INTRODUCCIÓN}

El artículo 121 de la $\mathrm{CE}^{1}$ somete al Estado Juez a una responsabilidad patrimonial objetiva, análoga — no en los mismos términos - a la prevista para el Estado Administración en su artículo $106.2^{2}$, teniendo a limine que reprochar al constituyente este blindaje por omisión de la Administración de Justicia respecto a las demás administraciones, omisión que ha dado pie a una legislación de desarrollo defectuosa que, además, ha sido interpretada por los tribunales de modo aun más restrictivo, imponiendo a los ciudadanos la aflicción de asumir unos daños y perjuicios que corresponden al poder públicoque los causa, pues en un Estado de derecho no están los ciudadanos a su servicio cual si fueran súbditos, sino precisamente al contrario, es el Estado en cada uno de sus tres ámbitos de poder (como Legislador, Administrador y Juez) el que está al

1 Art. 121 CE: «Los daños causados por error judicial, así como los que sean consecuencia del funcionamiento anormal de la Administración de Justicia, darán derecho a una indemnización a cargo del Estado, conforme a la ley».

2 Art. 106.2 CE: «Los particulares, en los términos previstos por la ley, tendrán derecho a ser indemnizados por toda lesión que sufran en cualquiera de sus bienes y derechos, salvo en los casos de fuerza mayor, siempre que la lesión sea consecuencia del funcionamiento de los servicios públicos».

UNED. Teoría y Realidad Constitucional, núm. 38, 2016, pp. 411-431 
servicio de los ciudadanos, y debe indemnizarles si le causa daños por su funcionamiento normal o anormal ${ }^{3}$.

El presente trabajo pretende en primer lugar describir los precedentes históricos de este artículo 121 de la CE, su posterior desarrollo legislativo ${ }^{4}$ escandalosamente restrictivo, la interpretación jurisprudencial de dichas normas reduplicadamente reductora y palmariamente inconstitucional, considerada desde la perspectiva sistemática del conjunto que forman los artículos 17 , 24 y los citados 106.2 y 121 de la CE, para continuar comparando estos referentes con las previsiones constitucionales y legislativas de otros estados europeos reforzando las merecidas críticas a la legislación y a la jurisprudencia españolas. El trabajo termina con concretas propuestas interpretativas y de lege ferenda.

\section{PRECEDENTES Y DESARROLLO LEGISLATIVO}

\section{Precedentes históricos}

\section{A) Situación anterior al siglo XIX}

En tiempos de la monarquía absoluta se confundía la figura del Rey y la del Estado — «L'État, c'est moi»—, y el monarca era el «dueño de la Justicia». Los jueces nombrados por el rey llegaron en ciertas épocas y lugares a participar con lucro en la penas pecuniarias que ellos mismos imponían, e incluso las llamadas penas «arbitrarias» de esta naturaleza se repartían por mitades entre el juez y la Cámara real en Castilla, al igual que los bienes decomisados; y, en fin, al ser Dios el origen del poder real, primero directo y luego a través del pueblo, consecuentemente también lo era del munus et ius puniendi del Estado y el ejercicio real del derecho de gracia venía a ser el cierre de este poder omnímodo. En este contexto, que legitimaba incluso la tortura para que siempre funcionara la Administración de justicia, la imposibilidad de exigencia de cualquier responsabilidad al juzgador era también absoluta, siendo obligación del súbdito aceptar los daños y perjuicios que el sistema judicial le provocase ${ }^{5}$.

3 Esta responsabilidad patrimonial del Estado Administración, Juez y Legislador forma parte del capítulo más amplio de la llamada «responsabilidad pública» (J.J. VAZQUeZ SEIJAS, «Introducción», en Manual de Responsabilidad Pública», VVAA Dirección J. De Fuentes Bardají, Ministerio de Justicia/Aranzadi, Navarra, p. 73). Sin duda una de las consecuencias de la Revolución francesa fue la reconversión del súbdito en ciudadano, que en el Reino Unido llevó a reinterpretar el tradicional principio de la Monarquía absoluta The King can do not wrong, en el sentido de que si se equivoca un poder público debe responder, interpretando el «no puede» por «no debe» o por un no puede en sentido moral. El artículo 10 de la CE así lo confirma.

4 Arts. 292 a 296 LOPJ.

5 Sobre la justicia penal en esta época puede verse Tomas y Valiente, F., El Derecho penal de la monarquia absoluta (Siglos XVI, XVII y XVIII), Tecnos, Madrid 1969. 
La vigencia de la inconciliabilidad de los conceptos de soberanía — podery responsabilidad — the King can do not wrong - tenía un especial arraigo en el ámbito de la administración pública en general ${ }^{6} \mathrm{y}$ de la administración de justicia en particular igualmente muy vinculada al rey, circunstancia que explica la tardía implantación de la responsabilidad extracontractual de los poderes públicos por daños y perjuicios - la tradicional culpa aquiliana - frente a los ciudadanos. Como recuerda ARDANT ${ }^{7}$, la independencia judicial, como encarnación de parte de esa soberanía — poder-, la intangibilidad de la cosa juzgada, la posible inducción a error a la administración de justicia por los justiciables y, posiblemente como motivo más poderoso que hoy sobrevive, el incremento del gasto público que tal responsabilidad supondría, han sido y siguen siendo razones para blindar este sector público frente a responsabilidades pecuniarias por daños y perjuicios a los ciudadanos.

En este contexto no resulta muy edificante afirmar que «La Justicia ...se administra en nombre del Rey...» (art. 117.1 CE), tradicional «vicarismo» proveniente de las Constituciones de 1812, 1845, 1869 y 1876 (que aun no conformaban una monarquía plenamente parlamentaria) y también de la franquista Ley Orgánica del Estado que declaraba igualmente que la Justicia se administraba «en nombre del Jefe del Estado». Más clara hubiera sido la fórmula de la Constitución de 1931 según la cual «La Justicia se administra en nombre del Estado», o la utilizada por la Constitución Italiana de 1947 — «La Justicia será administrada en nombre del pueblo»— y por la Ley Fundamental de Bonn — «Todo poder emana del pueblo... (y) es ejercido por órganos particulares de los poderes legislativo, ejecutivo y judicial»—. Esta «competencia real», aun cuando sólo tenga un valor simbólico, no deja de ser un factor más que dificulta la aun pendiente erradicación de la residual maiestas de la tan vinculada al rey administración de Justicia, de su irresponsabilidad en la generación de daños y perjuicios hoy excluidos por vía legal y/o jurisprudencial y, en definitiva, de su heredada «divinización» proveniente del ancien régime frente a la «secularización» y plena sumisión a los derechos del ciudadano de los restantes poderes públicos.

\section{B) Evolución en la era constitucional}

Las Constituciones históricas de 1812, 1837, 1845, 1869 y 1876 limitaban la responsabilidad de la actividad jurisdiccional a la personal de los jueces y magistrados por infracción de ley y/o por delito. Es la Constitución de 1931 la que, además de hacer referencia a la «responsabilidad civil y criminal en la que puedan

6 Chemerinsky, E., «Against Soverign Immunity», Stanford law review, Vol. 53, mayo 2001, pp. 1201-1224.

7 La responsabilité de l'Etat du fait de la fonction jurisdictionielle, París 1956, pp. 171 y ss. 
incurrir los jueces, magistrados y fiscales» (art. 99), declaraba el «derecho a ser indemnizado por los perjuicios que se le irroguen por error judicial o delitos de los funcionarios judiciales en el ejercicio de sus cargos, conforme determinen las leyes. El Estado será subsidiariamente responsable de estas indemnizaciones» (art. 106); en Francia hasta una ley de 7 de febrero de 1933, que modificó el artículo 505-2. ${ }^{\circ}$ del Code de Procédure civile, no se reconoció la responsabilidad directa del Estado y sólo en caso de la condena de un juez como responsable civil, sin perjuicio de la acción de repetición o regreso.

La Ley provisional sobre organización del Poder judicial de 15 de septiembre de 1870, regulaba en sus artículos 260 a 266 la responsabilidad de jueces y magistrados por infracción de «las leyes por negligencia o ignorancia inexcusables», circunstancia a verificar en procedimiento ante el Tribunal «inmediatamente superior al que hubiere incurrido en ella, y si el infractor perteneciere al Tribunal Supremo, por el pleno del mismo excluido el infractor. Se trata de una responsabilidad de las personas físicas y no del Estado, ni siquiera en régimen subsidiario, responsabilidad que en los supuestos delictivos el CP de $1870-\mathrm{y}$ los anteriores de 1822, 1848 y 1850 - tampoco la incluía al regularla en términos generales en sus artículos 20 y 21, situación que se modificó parcialmente en el CP de 1928 — art. 78, 3. - al admitirla cuando «El Estado, la Provincia y el Municipio» no actuara en servicios «derivados de sus facultades como Poder y Administración», pero que el CP de 1932 derogó volviendo a la regulación de 1870 , sin perjuicio de la vía administrativa anunciada en mencionado artículo 106 de la Constitución. En el CP de 1944 se mantiene la misma situación, que se prorroga en el de 1973 y en la reforma de 1983, si bien la jurisprudencia venía reconociendo la responsabilidad civil subsidiaria del Estado por delitos cometidos por funcionarios públicos. Y es finalmente el CP de 1995 el que se reconoce expresamente esta responsabilidad en su artículo 121, cuya interpretación resume el Acuerdo del Pleno no jurisdiccional de la Sala Segunda TS de 26 de mayo de 2000.

Pero volviendo a la responsabilidad patrimonial directa del Estado con anterioridad a la vigente LOPJ de 1985, no está demás recordar que la implantación de la responsabilidad extracontractual de la Administración ha seguido vías distintas en los diversos países, pues así como en Francia fue la jurisprudencia quien la introdujo, en Italia provino de la aplicación de los preceptos civiles reguladores de esta responsabilidad en general, y fue en España y en el Derecho inglés donde se precisaron normas específicas, que en nuestro país arrancan de la Constitución de 1931, del Estatuto municipal de 1935, posteriormente de las leyes de expropiación forzosa de 1954 y de Régimen local — texto refundido de 1955-, y de modo genérico, como precedente más inmediato de la actual regulación, de los artículos 40 y 41 de la Ley de Régimen Jurídico de la Administración del Estado de 1957. En la actualidad regulan esta materia los artículos 139 y siguientes de la Ley de Régimen jurídico de las Administraciones públicas y del Procedimiento Administrativo Común 30/1992 de 26 de noviembre y, a partir del 2 de octu- 
bre del presente año —-2016 - los artículos 32 a 35 de la Ley 40/2015 de 1 de octubre de Régimen jurídico del Sector público ${ }^{8}$.

¿En qué situación se encontraba la Administración de Justicia respecto a las previsiones de esta LRJAE de 1957?. Se ha considerado tal cuestión como «controvertida», aun cuando la doctrina administrativa venía excluyendo de este ámbito la responsabilidad de los órganos judiciales, pues la referencia del artículo 40 de la citada ley a los «servicios públicos» daba pié a configurar el concepto de Administración del Estado en un sentido subjetivo, excluyendo a los poderes legislativo y judicial, apoyándose en tal sentido también en la previsión del artículo 49 que remitía «la responsabilidad civil, penal y disciplinaria de los militares y funcionarios de las Carreras Judicial y Fiscal» a «las disposiciones especiales por las que se rigen», es decir, que sólo indirectamente podría responder el Estado por funcionamiento de la Administración de Justicia, sin posibilidad de encontrar fundamento legal para un responsabilidad patrimonial objetiva como la declarada el tan citado artículo 40, salvo el supuesto excepcional y específico derivado recurso de revisión resuelto con absolución del antes condenado (art. 960 LECr, procedente de la reforma introducida por la Ley de 24 de junio de 1933), primer supuesto de responsabilidad patrimonial directa del Estado?.

\section{C) Regulación legal vigente}

La actual regulación de la responsabilidad patrimonial del Estado, por el normal o anormal funcionamiento de la Administración de Justicia, se esquematiza del siguiente $\operatorname{modo}^{10}$ :

8 Garcia de Enterría, E., Los principios de la nueva Ley de Expropiación Forzosa, I.E.P., Madrid 1956. PARADA VAZQUez, R., Régimen jurídico de las administraciones públicas y procedimiento administrativo común, Marcial Pons, Madrid 1993, pp. 415 y ss. J.J. VazQuez Seijas, «Introducción», en Manual de Responsabilidad Pública», cit., pp. 76 y ss.

9 Martin Rebollo, L.: La responsabilidad patrimonial de la Administración en la jurisprudencia, Civitas, Madrid 1977, pp. 100 y ss. «La responsabilidad por el funcionamiento de la Administración de Justicia (el art. 121 de la Constitución y las bases de su desarrollo)», Documentación jurídica, 1985, n. ${ }^{\circ}$ 45-46.

10 Montero Daroca, J., Responsabilidad civil del juez y del Estado por la actuación del Poder judicial. Tecnos, Madrid 1988. Guzmán FlujA, V.C., «La extensión del principio de responsabilidad del Estado a la actividad de la Administración de Justicia», Dereito Vol. III, n. ${ }^{\circ}$ 1, 1994, pp. 107-131. GonzÁlez PÉrez, J., Responsabilidad patrimonial de las administraciones públicas, Cívitas, Madrid 1996, pp. 91 y ss. EsPINOSA DE RUEDA Jover, M., «Resarcimiento de los daños causados por las actuaciones procesales», Revista jurídica. Región de Murcia, Col. Abogados de Murcia, 1995. Acosta Gallo, P., La responsabilidad del Estado-Juez: error judicial y funcionamiento anormal de la Administración de Justicia, Montecorvo, Madrid, 2005. Calvo Corbella, J.C., «Responsabilidad de las Administraciones Públicas en sectores específicos», Manual de Responsabilidad Pública (obra colectiva), cit., pp. 724 y ss. GonZÁlez Alonso, A., Responsabilidad patrimonial del Estado en la Administración de Justicia, Tirant lo Blanch, Valencia 2012. RodRíguez RAmos, L., «La irresponsabilidad patrimonial de la Administración de Justicia», Diario La ley, 11 de abril 2012. «Irresponsabilidad patrimonial del Estado juzgador. Anacronísmos absolutistas o tatalitarios a erradicar», Diario La Ley 1 diciembre 2013. 
1. Responsabilidad subsidiaria, por los delitos cometidos por funcionarios al servicio de la Administración de Justicia, en el ejercicio de sus cargos (arts. 405 y ss LOPJ, $60 \mathrm{EOMF}^{11}$ y $121 \mathrm{CP}$ ).

2. Responsabilidad directa:

A) Por anormal funcionamiento de la Administración de Justicia:

1) En general (arts. 292.1, 293.2, 295 y 297 LOPJ).

2) Por los daños causados por dolo o culpa grave de los jueces y magistrados, a través de la declaración de responsabilidad de la Administración por error judicial o anormal funcionamiento, pudiendo lego repetir al infractor el importe de la indemnización, en los términos que luego se comentan (arts. 296 LOPJ, modificado por la LO 7/2015 de 21 de julio).

B) Por error judicial:

1) Por error judicial genérico (arts. 292.1, 293, 295 y 297 LOPJ).

2) Por errores judiciales específicos:

a. Prisión provisional del luego absuelto o sobreseído, por «inexistencia del hecho» (arts. 294 LOPJ, 9.5 PIDCP ${ }^{12}$ y 5.5 CEDH).

b. Recurso de revisión de sentencias firmes tornando la condenatoria en absolutoria (arts. 954 a 961 LECr y 14.6 PIDCP).

A estas oportunidades legales de resarcimiento se suma la posibilidad de reclamación directa a jueces, magistrados y/o fiscales por responsabilidad civil derivada de la penal, en el proceso penal (art. 37 L 40/2015 de 1 de octubre, de Régimen jurídico del sector publico).

Esta clasificación no es pacífica, pues la propia jurisprudencia y alguna doctrina consideran, por ejemplo, que el error judicial es una modalidad de anormal funcionamiento de la Administración de Justicia, y dada la interpretación superrestrictiva que la jurisprudencia hace de esta institución, como luego se verá, puede llegar a tener sentido tal consideración. Sin embargo, y partiendo de la limitación constitucional y legal de los supuestos generadores de responsabilidad patrimonial en la Administración de Justicia, que en contraste con las otras administraciones públicas se excluye su derivación del normal funcionamiento, lo más razonable sería considerar ambos supuestos (particularmente el error judicial) como actos que generan responsabilidad aun cuando se tratara de casos de anormal funcionamiento, pues de lo contrario carecería de sentido la exigencia, en el caso de error judicial, de una declaración jurisdiccional de su existencia

11 Estatuto Orgánico del Ministerio Fiscal (Ley 50/1981 de 30 de diciembre).

12 Pacto Internacional de Derechos civiles y políticos (Nueva York, 30 de abril de 1966, BOE de 30 de abril de 1977). 
previa a la reclamación administrativa, requisito inexistente en los supuestos de funcionamiento anormal que sólo requieren informe del CGPJ como luego se verá, y todo ello al margen de que se deba distinguir donde la Constitución distingue, máxime si aplicamos las debidas pautas de interpretación, particularmente la sistemática, previstas en el artículo 3 del CC.

Finalmente hay que hacer referencia a la reciente derogación de los artículos 411 a 413 de la LOPJ, por la reforma introducida por LO 7/2015 de 21 de julio, que impide la reclamación directa a los jueces, magistrados y fiscales de responsabilidad civil por dolo o culpa, pues sólo el Ministerio de Justicia podría reclamarles la correspondiente indemnización por dolo o culpa grave (ya no por culpa que no sea grave) si previamente ha sido condenado el Estado Juez por responsabilidad patrimonial objetiva, en concepto de error judicial o anormal funcionamiento de la Administración de Justicia. Se trata de un nuevo blindaje de responsabilidad de jueces, magistrado y fiscales que aumenta el desequilibrio entre la libertad y la responsabilidad de estos funcionarios al ejercer sus funciones públicas. Cierto que la L 40/2015 de 1 de octubre, del Régimen jurídico del Sector público, ha generalizado en su artículo 36 a todas las autoridades y funcionarios este veto a reclamar directamente a responsabilidad civil por dolo o culpa grave, exigiendo que se sea la Administración a quién se reclame la correspondiente indemnización como responsabilidad patrimonial objetiva, otorgando a ésta la facultad de repetir al funcionario, pero tan cierto es también que la responsabilidad patrimonial del Estado Administración lo es por el normal o anormal funcionamiento de los servicios públicos, resultando en las práctica más amplia que la exigible al Estado Juez.

Al ser la Administración de Justicia una competencia estatal, sin perjuicio de las transferencias a las Comunidades autónomas de competencias sobre infraestructuras y funcionarios que no ejercen funciones directamente jurisdiccionales, es al Estado a través del Ministerio de Justicia al que corresponde resolver en vía administrativa recibir y tramitar estos expedientes de reclamación de indemnizaciones por daños derivados del ejercicio del Poder Judicial (STS, Sala $3 .^{a}$, Sección 2. de 7 de febrero de 2004).

\section{Causas y efectos de este «blindaje» de la Administración de Justicia}

¿Por qué hasta 1933 no se reconoció, y de modo muy parcial, la responsabilidad patrimonial directa de la Administración de Justicia?, ¿por qué se ha mantenido después un trato diferencial "privilegiado» respecto a las demás administraciones públicas en la propia $\mathrm{CE}$ y en las normas de desarrollo?, ¿qué consecuencias tienen en el actual funcionamiento de la Administración de Justicia estos amplios márgenes de irresponsabilidad patrimonial?. Estas son la preguntas a responder muy brevemente, antes de entrar en el núcleo del presente artículo. 
La respuesta formal a la primera pregunta es la especial vinculación del ius puniendi estatal a la soberanía y al absoluto poder real hasta el siglo xIx, tal y como muy someramente se ha recordado, y desde una perspectiva más sociopolítica podría hacerse extensiva a algunos sectores de la Administración de Justicia, particularmente en el orden penal, lo que en 1936 decía Karadge-Iskrow ${ }^{13}$ para explicar el porque no se indemnizaban las detenciones y prisiones preventivas seguida de absolución, que en resumen era la procedencia de la mayor parte de la población penal de los sectores más desfavorecidos, la prevalencia de la protección de la propiedad y la sensación de los poderes fácticos, de los legisladores y de los jueces de que no van a ser víctimas de daños y perjuicios procedentes de la Administración de Justicia. Como decía Lopez Rey ${ }^{14}$, los sujetos pasivos de siempre del Derecho penal, los que están en las cárceles en proporción más elevados, son «los pobres diablos» de la sociedad, que se van a conformar con lo que les den y no van a reclamar lo que no les den. A todo ello habría que añadir el alto coste económico que para el Fisco tendría la indemnización de daños y perjuicios causados por el normal y anormal funcionamiento de la Administración de Justicia, y las exigencias de cambio real que dicha administración precisaría para no generar tantos daños y perjuicios, cambio que a su vez requeriría nuevos gastos (duplicar el número de jueces, implantar una oficina judicial que funcionara como la Agencia Tributaria o como la Seguridad Social, erradicar las dilaciones indebidas, etc.) y un cambio de mentalidad corporativo y de no pocos jueces y magistrados («descorporativizar» el Consejo General del Poder Judicial, considerarse funcionarios al servicio de los ciudadanos sin hacerles esperar en los pasillos de los órganos jurisdiccionales, etc.). En definitiva, reformas costosas y profundas que no se quieren afrontar urgidos por el coste de los daños y perjuicios derivados el mal funcionamiento de la Administración de Justicia, que se viene considerando «normal» desde un punto de vista estadístico, aunque sea «anormal» al ser contrario a las normas jurídicas que lo regulan.

Y respondiendo a la tercera cuestión, las consecuencias que se derivan de este «blindaje» de la Administración de Justicia, frente a indemnizaciones por daños y perjuicios, están en parte enunciadas en la respuesta al párrafo anterior. Dichas consecuencias pueden diferenciarse en diversos apartados vinculados por sucesivas derivadas. La primera es la falta de indemnización por daños y perjuicios sufridos por los ciudadanos a consecuencia del normal y, sobre todo, anormal funcionamiento de la Administración de Justicia. La segunda, la falta de motivación económica del Estado (especialmente de los poderes Ejecutivo y Legislativo) para acometer con decisión y urgencia las reformas que reclama la Justicia, al no costarle dinero esos daños y perjuicios que sufren los ciudadanos. La tercera, el man-

13 «Notes sur la responsabilité de la puissance publique en droit interne», Archives de Philosopbie du Droit et de Sociologie Juridique, reeditada Detleu Auverman KG, Glashütten im Taunus 1972, pp. 196 y ss.

14 Manuel López-Rey y Arrojo, criminólogo y discípulo de Jiménez de Asúa, exiliado que retornó a España tras la muerte de Franco, en conversación con el autor de este artículo. 
tenimiento del statu quo sin que se produzcan tales inversiones y reformas, a pesar de que este inmovilismo no sólo afecte a los ciudadanos justiciables sino también a toda la sociedad y a la economía nacional, por las consecuencias que una mala y sobre todo tardía Justicia genera. En este estado de anemia tiene especial importancia la ausencia de realidad y efectividad de los derechos fundamentales implicados, particularmente los relativos a la tutela judicial efectiva (arts. 9.1, y 24 CE) pero también a la libertad (art. $17 \mathrm{CE}$ ), agravados por la devaluación del recurso de amparo constitucional tras la últimas barreras a limine en las admisión de tales demandas.

\section{PERVERSA INTERPRETACIÓN JURISPRUDENCIAL DEL DERECHO APLICABLE}

\section{1. «Funcionamiento anormal»}

\section{A) Concepto}

La diferenciación entre funcionamiento normal y anormal de la Administración de Justicia no tiene relevancia en el ámbito de las restantes administraciones públicas, pues éstas responden tanto en supuestos de normalidad como de anormalidad, siempre que causen daños, mientras que aquélla sólo acaba respondiendo por funcionamientos anormales y, además, aplicando un concepto restrictivo de «anormalidad» como ser verá de inmediato, pues la distinción que establece el artículo 121 de la CE entre «error judicial» y «anormal funcionamiento» que invitaba a incluir el primer concepto en el ámbito del funcionamiento normal — «equivocarse es de sabios»—, ha sido traicionada por la jurisprudencia como ya se anunció.

Antes de entrar en la doctrina jurisprudencial sobre el tema, hay que desplegar el panorama de opciones en lo que a la interpretación literal del término «anormal» se refiere, y abreviando pasos en el sorites se llega a una primera conclusión: anormal es lo que está fuera de lo «normal», puesto que el significado del «alfa privativa» es la exclusión del ámbito de la palabra a la que se aplica. En este caso anormal significará todo lo que no es «normal», lo que está fuera de lo normal y no necesariamente lo contrario a lo normal que precisaría el uso del prefijo «anti» $\mathrm{O}$ «contra».

¿Y qué se entiende por «normal»?, genéricamente lo que se ajusta a la norma, pero surge la duda de si se trata de una normalidad jurídica, en este caso, lo que se ajusta a la ley, o de una «normalidad estadística», es decir, lo que acaece «de ordinario», en la «realidad» y no en el mundo ideal de la norma. Por ejemplo, en el ámbito procesal penal el llamado «procedimiento ordinario» es el «normal» según la LECr, pero estadísticamente el normal es el «procedimiento abreviado» aun cuando en la normalidad jurídica se le considere un procedimiento 
especial. Análoga opción surge, por ejemplo, en el cumplimiento - y en el incumplimiento- de los plazos por los órganos jurisdiccionales (los abogados o los cumplen o declinan en su derecho procesal, lo que supone que en su caso se identifican las dos acepciones al coincidir la normalidad estadística con el cumplimiento de la norma), ¿es anormal dictar una sentencia en el procedimiento abreviado después de transcurridos los cinco días desde la celebración del juicio, cuando el plazo legal exige lo contrario (art. 789.1 LECr)?, pues desde el punto de vista estadístico es evidente que no, pero desde la perspectiva de la norma, de lo que debe ser conforme a Derecho, la evidencia se torna en que sí.

Como era de esperar, y de modo particular en relación con las dilaciones indebidas $^{15}$, la jurisprudencia ha optado por el criterio estadístico, edulcorándolo con consideraciones simulatorias. En definitiva reitera la STS Sala 3. ${ }^{a}$, Sección $3 .{ }^{a}$ de 21 de octubre de 2001 (recordando otras anteriores de la Sección 6. ${ }^{a}$ de 21 de junio de 1996 y 28 de junio de 1999), que «el simple incumplimiento de los plazos procesales meramente aceleratorios constituye una irregularidad procesal que no comporta, pues, por sí misma, una anormalidad funcional que genere responsabilidad. Sí constituye anormalidad, en cambio, una tardanza, tomando en cuenta la duración del proceso en sus distintas fases, que sea reconocida por la conciencia jurídica y social como impropia de un Estado que propugna como uno de sus valores superiores la justicia y reconoce el derecho a una tutela judicial eficaz». En este mismo sentido pueden citarse otras muchas SSTS Sala 3. ${ }^{a}$ (entre otras, de la Sección 6. ${ }^{a}$ las de 5 de abril de 2006, 22 de enero de 2008 y A de 14 de enero de 2016).

El Tribunal Constitucional, también en relación con las dilaciones indebidas, ha evolucionado convirtiendo en criterio general lo que TOMAS Y VALIENTE expresó como voto particular en la STC 5/1985, de 23 de enero, diciendo que «el abrumador volumen de trabajo que pesa sobre determinados órganos jurisdiccionales» puede relevar de responsabilidad personal a los jueces y magistrados, pero «no priva a los ciudadanos de poder reaccionar frente a tales retrasos». Pero aunque el TC venga desde entonces admitiendo la tesis de la normalidad jurídica cierta, frente a la estadística dependiente de circunstancias materiales de volumen de trabajo y dotación de medios de los órganos judiciales (SSTC 31 y 195/1997 de 24 de febrero y 11 de noviembre, 58 y 184/1999 de 12 de abril y 11 de octubre, entre otras), no le concede especiales consecuencias a la declaración de haberse lesionado el derecho fundamental correspondiente, de ahí el voto articular de Mendizabal Allende, en la STC 103/2000 de 3 de marzo, reclamando efectividad a las declaraciones de dilaciones indebidas en los recursos de amparo, frente a su valor meramente simbólico. $Y$ en este punto hay que citar la perver-

15 Garcia Manzano, P., «Responsabilidad del Estado por funcionamiento anormal de la Administración de Justicia, Poder Judicial, número especial V, pp. 301 y ss. Diaz Delagado, J., La responsabilidad patrimonial del Estado por dilaciones indebidas en la Administración de Justicia, Ediciones siete, Valencia, 1990. 
sión que ha supuesto, primero una praxis jurisprudencial en el orden penal y luego la promulgación de una norma en el mismo sentido ${ }^{16}$, al obviar la responsabilidad patrimonial por dilaciones indebidas mediante la aplicación a los condenados en un proceso penal de una circunstancia atenuante, y se trata de una perversión porque carece de sentido sustituir una indemnización por una atenuación de la pena a modo de prescripción o de indulto parcial, exigiendo además que se trate de una dilación «extraordinaria».

\section{B) Supuestos concretos de anormalidad}

No es este el momento de enumerar todos los posibles supuestos de anormal funcionamiento de la Administración de Justicia ${ }^{17}$. Baste a estos efectos enunciativos con tratar sumariamente las ya mencionadas reclamaciones por dilaciones indebidas y las demandas por pérdida o deterioro de objetos cautelarmente intervenidos durante el proceso o por la colaboración de ajenos al proceso en el mismo.

Sobre las dilaciones indebidas sólo insistir en la diferente conceptualización de las mismas que se produce en la jurisprudencia del TC y en la de la Sala 3. ${ }^{a}$ del TS, como ya se ha visto en el epígrafe anterior, disparidad de criterios que no se concilia con una vigencia real y efectiva del derecho fundamental a un proceso sin dilaciones indebidas. Otra cosa sería que las dilaciones indebidas, por incumplimiento de los plazos legales o por paralizaciones innecesarias del procedimiento, generen o no daños efectivos, evaluables e individualizables merecedores de indemnización.

También se han producido demandas de indemnización por anormal funcionamiento de la Administración de Justicia por pérdida o deterioro de objetos en depósito judicial durante el proceso (arts. 374.1-3. ${ }^{\circ} \mathrm{CP}, 459$ LOPJ, 1785 a 1789 CC — depósito necesario, judicial o secuestro, y no voluntario-, 334 y 338 LECr) y por colaboraciones reclamadas por jueces y tribunales en el curso del proceso y en la ejecución de lo resuelto (art. 17.1 LOPJ). Respecto a los primeros, la jurisprudencia ha confirmado que no se trata de depósitos voluntarios que se rigen por el Derecho privado sino que, al ser judiciales — secuestros—- se regulan por las normas de Derecho público a la hora de devolver tales objetos a los que resultaran absueltos, siendo indemnizable la pérdida de los mismos (SSTS, Sala 3. a , Sección 6. a de 18 de noviembre de 1999 y 13 de octubre de 2004, y Sección $4 .^{a}$, de 8 de junio de 2011); no suelen considerarse objeto de funcionamiento anormal los deterioros por el trascurso del tiempo o incluso por el uso (de vehí-

16 Circunstancia atenuante 6 (artículo $21 \mathrm{CP}$ ), procedente de la reforma del CP por LO 5/2010, de 22 de junio, que reza así: «La dilación extraordinaria e indebida en la tramitación del procedimiento, siempre que no sea atribuible al propio inculpado y que no guarde proporción con la complejidad de la causa».

17 ManZanares Samaniego, J.L., «Otros funcionamientos anormales de la Administración de Justicia», Diario La Ley, 24 de enero de 2012. 
culos por la policía, al amparo del artículo 341.1-3. ${ }^{a} \mathrm{CP}$ ), lo que se considera injustificable. Respecto a los daños sufridos por los depositarios ajenos al proceso penal o por quienes cedieron espacios para los depósitos, las SSTS, Sala 3. ${ }^{a}$, Sección $4{ }^{a}{ }^{a}$ de 13 de mayo y 8 de junio de 2011 reconocen sin reservas el derecho a su indemnización por la vía del funcionamiento anormal de la Administración de Justicia.

\section{C) Necesaria justificación de los daños y de la causalidad}

Como declara el artículo 292.2 LOPJ «el daño alegado habrá de ser efectivo, evaluable económicamente e individualizado con relación a una persona o grupo de personas». Obviamente deberá igualmente acreditarse la relación de causalidad entre el funcionamiento anormal y el daño, excluyéndose expresamente los casos de «fuerza mayor» (art. 292.1 LOPJ).

Que el daño sea «efectivo» quiere decir que se excluyen los hipotéticos o los futuros. Comprende tanto el daño emergente (pérdidas y gastos derivados de la lesión) como el lucro cesante (lo que se ha dejado de ganar a consecuencia de la misma). Los daños pueden ser materiales y morales, entendiendo por éstos los padecimientos físicos o psíquicos derivados de la lesión, conculcación de derechos inmateriales de la persona, del derecho de autodeterminación o de derechos fundamentales o de la personalidad (STC 53/1985 de 11 de abril y SSTS, Sala 3. Sección $6 .{ }^{a}$ de 3 de octubre de 2000, 24 de abril de 2003 y 4 de diciembre de 2009, y Sección 3. a de 6 de abril de 2006).

\section{D) Filtro previo corporativo}

Como se mencionó en el primer apartado de este artículo, aun cuando la LOPJ no lo previera, en la Disposición adicional 2. ${ }^{a}$ del Reglamento de los procedimientos de las administraciones públicas en materia de responsabilidad patrimonial, aprobado por el RD 429/1993 de 25 de marzo, se manifestó: «En las reclamaciones en materia de responsabilidad patrimonial del Estado por el funcionamiento penal de la Administración de Justicia, será preceptivo el informe del Consejo General del Poder Judicial. El plazo para dictar resolución quedará suspendido durante dos meses desde la solicitud del informe del Consejo». Esta disposición reglamentaria, aun vigente, ha sido elevada a rango de ley por la L 39/2015 reguladora del Procedimiento administrativo común de las administraciones públicas en su artículo 81.3.

Además de este trámite prejudicial mencionado, la LOPJ en su artículo 293.2 dispone que el derecho a solicitar la indemnización prescribe al año a partir del día en que pudo ejercitarse, que se presentara la solicitud ante el Ministerio de Justicia y se seguirá la tramitación prevista en las «normas reguladoras de la 
responsabilidad patrimonial del Estado», es decir, la contenidas en el RD 429/1993 antes citado, que aprueba el Reglamento de tales procedimientos, que prevé un plazo de seis meses o de treinta días, según se siga el procedimiento común o el abreviado, para que se considere negativamente resuelto el expediente por silencio administrativo negativo. Con anterioridad a formalizar legalmente el informe del CGPJ en estos expedientes en virtud de la citad Disposición adicional 2. ${ }^{a}$ del Reglamento de los procedimientos de las administraciones públicas en materia de responsabilidad patrimonial, aprobado por el RD 429/1993 de 25 de marzo, dicho Consejo ya había dispuesto en el Acuerdo de 16 de abril de 1986 que era procedente «emitir por el Consejo los informes que le sean recabados por el Ministerio de Justicia en los expedientes ante él suscitados sobre reclamación de indemnización por anormal funcionamiento de la Administración de Justicia, concretado dicho informe a determinar si se ha producido el pretendido funcionamiento defectuoso...», fijando criterios ambiguos relativos a la prisión provisional indebidamente cumplida; posteriormente, en reuniones de los días 14 y 18 de enero de 1992, la Comisión de Estudios e Informes del Consejo terminó declarando que el informe en tales supuestos excluía cualquier pronunciamiento sobre la procedencia de la reclamación, de la existencia de relación de causalidad, del perjuicio o de la cuantía de la indemnización, debiendo en cambio pronunciarse expresamente, «cuando así derive de las actuaciones practicadas, acera de la improcedencia de la acción de repetir que asiste al Estado a tenor de lo previsto en el artículo 296 de la LOPJ, guardando silencio en caso contrario», planteamiento este último claramente defensor los jueces y magistrados implicados.

La resolución será recurrible ante la Sala de lo Contencioso-administrativo de la Audiencia Nacional (art. 11 LJCA) y a su vez la sentencia de instancia lo será en casación ante la Sala tercera del Tribunal Supremo (arts. 12 y 86 LJCA).

\section{El error judicial genérico}

\section{A) Concepto jurisprudencial}

No existe un concepto legal de «error judicial» tratándose por tanto de un concepto jurídico indeterminado, que sólo por vía jurisprudencial y doctrinal puede explicitarse. Error es lo contrario de acierto y en el presente caso errónea será una resolución judicial (sentencia, auto o providencia) que no se ajuste a la verdad o realidad fáctica (supuesto de hecho sobre el que se basa la resolución: da mibi factum dabo tibi ius) o/y jurídica (hay también «hechos jurídicos», como la «resolución arbitraria» en los delitos de prevaricación, y por eso los penalistas prefieren utilizar los términos «error de tipo» $\mathrm{y}$ «error de prohibición», en vez de «error de hecho y de derecho»). En principio «equivocarse», cometer un error de iure vel de facto habría que considerarlo como algo fruto de un funcionamiento 
«normal» de la Administración de Justicia, en contraste el funcionamiento «anormal» que el artículo 121 de la CE expresa como alternativa, y en tal sentido fue interpretada antes de su configuración jurisprudencial ${ }^{18}$, pero como se verá de inmediato las Salas del Tribunal Supremo han pervertido tan lógica interpretación, convirtiendo el «error» en «aberración» y, por ende, en una modalidad más del «funcionamiento anormal», reconociéndolo además expresamente ${ }^{19}$.

La existencia de error, al margen de que genere o no daños al sujeto pasivo del mismo, requiere como se ha visto una «decisión judicial que expresamente lo reconozca» (art. 293.1 LOPJ), en contraste con el «funcionamiento anormal»y «la prisión preventiva ... por inexistencia del hecho imputado» que no requieren dicha declaración previa, si bien en caso de denegación de la indemnización sí terminará declarando el orden jurisdiccional contencioso administrativo su existencia o inexistencia.

Como ya se ha anunciado, la jurisprudencia ha reducido la extensión significativa del sustantivo «error» acudiendo a su adjetivación acumulativamente restrictiva, pues sólo considera error relevante merecedor de indemnización el que merezca la sucesiva cualificación que resume del siguiente modo la STS, Sala $3 .^{a}$, Sección $1 .^{a}$, FD tercero de 21 de julio de 2011, citando la de la misma sala de 3 de octubre de 2008: ha de ser «el error 'craso', 'patente', 'indubitado', 'incontestable', 'flagrante', que haya provocado 'conclusiones fácticas o jurídicas ilógicas, irracionales, esperpénticas o absurdas'. Y en relación con el error judicial en la interpretación o aplicación de la Ley, hemos señalado que sólo cabe su apreciación cuando el órgano judicial ha 'actuado abiertamente fuera de los cauces legales', realizando 'una aplicación del derecho basada en normas inexistentes o entendidas fuera de su sentido'. En todo caso ... no existe error judicial 'cuando el Tribunal mantiene un criterio racional y explicable dentro de las normas de la hermenéutica jurídica', 'ni cuando se trate de interpretaciones de la norma que, acertada o equívocamente, obedezcan a un proceso lógico', o, dicho de otro modo, que no cabe atacar por este procedimiento excepcional 'conclusiones que no resulten ilógicas o irracionales», dado que 'no es el desacierto lo que trata de corregir la declaración de error judicial, sino la desatención, la desidia o la falta de interés jurídico, conceptos introductores de un factor de desorden, originador del deber, a cargo del Estado, de indemnizar los daños causados directamente, sin necesidad de declarar la culpabilidad del juzgador». Y la misma sentencia remata esta declaración citando como reiterativas de su contenido las siguientes SS de la misma Sala y Sección: 27 de marzo y 20 de junio de 2006, 12 de marzo, 30 de

18 Por ejemplo, Serrano Alberca, J.M. (Autor de este referente, en la obra colectiva dirigida por Garrido Falla, F.), Comentarios a la Constitución, Cívitas, Madrid 1985, pp. 1.732 y ss.

19 Calvo Corbella, J.C., «Responsabilidad de las Administraciones Públicas en sectores específicos», Manual de Responsabilidad Pública (obra colectiva), Ministerio de Justicia/Thomson Reuters-Aranzadi, Navarra 2010, pp. 729 y 730. Manzanares SAmAniego, J.L., «El error judicial», Diario La Ley, 21 de noviembre de 2011 . 
mayo y 14 de septiembre de 2007, 30 de abril y 9 de julio de 2008. En igual sentido se han pronunciado otras resoluciones del mismo tribunal ${ }^{20}$.

\section{B) Otros requisitos y conclusiones parciales}

También en este caso deben acreditarse los daños efectivos, evaluables económicamente e individualizables (art. 292.2 LOPJ), así como la relación de causalidad entre el error y tales daños, excluyéndose también la fuerza mayor (art. 292.1 LOPJ).

La acción para instar el reconocimiento judicial del error tiene un plazo de tres meses desde la firmeza de la resolución, se condenará en costas al peticionario si no se le reconoce el error, habrán de agotarse los recursos ordinarios contra la resolución errónea (no así los extraordinarios ni la solicitud de nulidad, al tratarse de un plazo de caducidad que no se interrumpe en tales casos, STS, Sala especial del art. 61 de 1 de marzo de 1996 y SSTS, Sala 3. ${ }^{a}$, Sección 2. ${ }^{a}$ de 21 de mayo 1998 y 14 de abril de 2009). Estos y otras previsiones procesales menos relevantes están previstas en el artículo 293.1 LOPJ.

Y la acción para reclamar ante el Ministerio de Justicia la indemnización, una vez declarado el error por la Sala correspondiente del Tribunal Supremo, es de un año (art. 293.2 LOPJ).

De lo dicho se desprenden las siguientes conclusiones parciales:

1. El error de hecho o de derecho — de facto o de iure — ha sido jurisprudencialmente restringido sin que la fórmula legal literalmente lo propicie.

2. Tal restricción y configuración del error judicial, que sólo puede radicar en resoluciones de juzgados y tribunales y por lo tanto protagonizado por jueces y magistrados, inevitablemente se introduce en el ámbito del «dolo o culpa» generador de responsabilidad individual y subjetiva, e incluso de responsabilidad penal por prevaricación dolosa o imprudente (art. 446 y 447 CP).

3. Además se está propiciando su inclusión en el ámbito del funcionamiento anormal de la Administración de Justicia, transmutando su naturaleza vinculada al normal funcionamiento de la misma. Un «error» debe considerarse normal, mientras que la «aberración», «la arbitrariedad»o «la irracionalidad» sí podría estimarse como funcionamiento anormal.

4. En definitiva, al recorte constitucional y legal de la responsabilidad patrimonial de la Administración de Justicia, cuya abolición de lege ferenda se reclama al final de este artículo, se suma una interpretación contra el

20 Entre las más recientes: Sala 3. ${ }^{\text {, }, ~ S e c . ~ 6 . ~}{ }^{\text {a }, ~ S ~ d e ~} 19$ octubre de 2015, Rec. 1453/2014 y A Secc. 1. a, de 14 de enero de 2016, Rec. 1059/2015.

UNED. Teoría y Realidad Constitucional, núm. 38, 2016, pp. 411-431 
justiciable restringiendo aun más su derecho a ser reparados en los daños y perjuicios que le ha causado dicha Administración.

5. Y, en fin, esta interpretación restrictiva puede hipotéticamente explicarse en una subconsciente autodefensa corporativa de los compañeros de orden jurisdiccional que hayan podido incurrir en el error.

\section{Errores judiciales especialmente regulados}

La legislación recoge tambiéndos errores específicos: las prisiones preventivas de quienes luego son absueltos y las sentencias condenatorias que se tornan absolutorias resuelto el correspondiente recurso de revisión.

\section{A) La prisión preventiva errónea}

El artículo 294 LOPJ ofrece una vía específica para que el absuelto, por sentencia o sobreseimiento, que haya sufrido prisión preventiva, pueda reclamar indemnización por los daños sufridos, si bien limita este derecho a los supuestos en que dicha absolución se base en la «inexistencia del hecho imputado».

Hasta la STS Sala 3. ${ }^{a}$, Sección 6. de 23 de noviembre de 2010, y tras iniciales vacilaciones, se venía admitiendo que la inexistencia del hecho podía ser «objetiva» (no había objeto de imputación o el objeto resultaba ser penalmente atípico) o «subjetiva» (no había hechos que vincularan el objeto de imputación existente con la persona absuelta). Esta doctrina, que excluía la indemnización por absoluciones derivadas de la presunción de inocencia - ausencia de pruebas suficientes- (p.e. STS, Sala 3. ${ }^{a}$, Sección 6. ${ }^{a}$, de 3 de octubre de 2007), no fue compartida por el TEDH (SS de 25 de abril de 2006 - Caso Puig Panella_y de 13 de julio de 2010 — Caso Tendam-). Los procedimientos en que se absuelve al acusado por la anulación de pruebas ilícitas o inválidas se consideran también insuficientes para acreditar la inexistencia del hecho (SSTS, Sala 3. ${ }^{a}$ de 25 de mayo de 2006, de 19 de septiembre de 2007 y 26 de mayo de 2010); otra cosa es que el hecho resulte atípico, pues en tales supuestos no existe hecho delictivo alguno y es indemnizable la prisión indebidamente sufrida (STS, Sala 3. ${ }^{\text {a de }} 20$ de octubre de 2010), o los supuestos en los que se retira la acusación por parte del fiscal, en los que generalmente se venía apreciando la inexistencia subjetiva del hecho y la procedencia de indemnización (SSTS, Sala $3 .{ }^{\text {a }}$ de 6 de octubre de 2006, 23 de junio y 10 de noviembre de 2010).

Pues bien, la referida sentencia de 23 de noviembre de $2010^{21}$, que ha sido reiteradamente confirmada con posterioridad (SSTS, Sala 3. ${ }^{a}$, Sección $4 .{ }^{a}$ de 24 de

21 Martí Martí, J., «La revisión de la doctrina del 'error judicial' en los supuestos de prisión preventiva seguida de absolución», Diario La Ley, 27 de abril de 2011. ManZanAres SAmaniego, J.L., «Otras 
mayo, 27 de junio, 10 de octubre y 23 de diciembre de 2011), ha regresado a la doctrina restrictiva o al menos estricta, en virtud de la cual sólo por inexistencia «objetiva» del hecho se merece indemnización por esta vía específica de error judicial, si bien y para colmo de sorpresa, la misma resolución declara que en los supuestos de inexistencia «subjetiva» se podrá lograr indemnización siguiendo la vía general del error judicial del artículo 293, declaración sorprendente tanto para este autor como para Martí Martí, pues por una parte y por la misma regla de tres se podría decir que los supuestos de absolución por aplicación de la presunción de inocencia también podrían tener encaje en se ámbito reclamatorio, y por otra y sobre todo porque, teniendo en cuenta el criterio superrestrictivo del concepto jurisprudencial del error judicial genérico antes examinado, no soportaría una prisión preventiva acordada que no encaje en el supuesto específico del artículo 293, todos los adjetivos descalificativos antes referidos que deben acompañar al error para su existencia.

\section{B) La sentencia errónea revisada}

Y en fin, sólo resta la referencia al supuesto indemnizatorio más antiguo en el ámbito de la Administración de Justicia que es, como se ha visto, el introducido en la reforma del artículo 960 de la LECr por la Ley de 24 de junio de 1933. Se trata de una segunda excepción a la irresponsabilidad de la Administración de Justicia en el ámbito de los daños y perjuicios causados por su funcionamiento normal. Es un craso error, pero no necesariamente imputable a dolo o culpa de los jueces o magistrados.

\section{DERECHO COMPARADO}

\section{Ausencia de trato diferencial constitucional}

Ni la Ley Fundamental de Bonn, ni la Constitución italiana, ni la Constitución francesa de 1958 contienen disposiciones similares a las mencionadas al inicio de este trabajo (art. $121 \mathrm{CE}$ ). Las dos primeras incluyen la responsabilidad patrimonial de la Administración de Justicia — por omisión de mención expresa en otro precepto- en la general del «ejercicio de una función pública» (Alemania, art. 34) o de «los funcionarios y empelados del Estado y de los entes públicos» (Italia, art. 28).

cuestiones sobre la responsabilidad patrimonial por prisión preventiva», Diario La Ley, 3 de enero de 2012. SANCHEz Morón, M., «El régimen jurídico de la responsabilidad patrimonial por error judicial en caso de prisión preventiva», Justicia administrativa, n. ${ }^{\circ} 55$, primer trimestre 2012. 


\section{La responsabilidad directa pero no objetiva}

En Italia ${ }^{22}$, partiendo del citado artículo 28 de la Constitución que se estimaba contenía también una responsabilidad directa y solidaria del Estado, hasta la Sentencia de la Corte constitucional 2/1968 de 14 de marzo no se consideró a los jueces y magistrados y en consecuencia a la Administración de Justicia inmersos en dicho precepto. La Ley 117/1988 de 13 de abril prevé la acción directa contra el Estado, que tiene la acción de regreso contra el magistrado.

En Alemania el parágrafo 839 del Código civil —BGB - preveía ya la responsabilidad de los jueces por dolo o culpa, y posteriormente la Ley Fundamental de 1949 en el citado artículo 34 incluyo sin dudas interpretativas la responsabilidad directa del Estado en supuestos de dolo o culpa grave del juez, que no responde directamente ante el dañado sino por la posterior repetición del Estado frente a él.

En Francia, la Ley de 5 de julio de 1972 reitera la responsabilidad directa del Estado por dolo, culpa grave o denegación de justicia de jueces y magistrados, matizando la Ley de 18 de enero de 1978, que modificó el artículo 11 del Estatuto de la Magistratura, que el perjudicado sólo podrá reclamar la indemnización al Estado y nunca directamente al juez, quién sólo pude ser objeto de reclamación por el Estado en ejercicio de la acción de regreso.

\section{La responsabilidad directa y objetiva}

El PIDCP (arts. 14.6 y 9.5) y el CEDH (art. 5.5) disponen la procedencia de indemnización en casos de revocación de sentencia condenatoria, detención o prisión ilegal - PIDCP — o contrarias a los supuestos descritos en el artículo 5.1 a $4-\mathrm{CEDH}-$.

En el derecho comparado continental se han ido acomodando sin discusión la responsabilidad objetiva y directa del Estado por la prisión provisional finalmente indebida, por el error judicial y por las dilaciones indebidas

En Alemania, el imputado que no es condenado tiene derecho a una indemnización por prisión preventiva, internamiento provisional, secuestro y privación provisional del permiso para conducir; si es en sentencia, en todo caso y sin las limitaciones españolas derivadas de la «inexistencia del hecho», y si es mediante sobreseimiento, sólo cuando deba ser sobreseído y no cuando lo sea a consecuencia de un acto de discrecionalidad, salvo que razones de justicia aconsejen lo contrario (parágrafos 2, I y II, y 3 de la Ley sobre la indemnización por medidas adoptadas en persecución penal — StrEG-). También se dispone la indemniza-

22 Villagomez Cebrian, A.J., «Responsabilidad y democratización del Poder Judicial en Italia: referencia al caso español», Boletín de Información del Ministerio de Justicia, 1987, pp. 3479 y ss. 
ción en caso de revisión de una sentencia condenatoria, indemnización a la que también tienen derecho las personas respecto a las que el condenado estuviera obligado a pagar alimentos (parágrafos $1,5,6$ y 11 StrEG) ${ }^{23}$. Pero además de estos supuestos específicos de responsabilidad patrimonial objetiva y directa del Estado Juez, el Código procesal penal —StPO- $\$ \$ 467$ y 467 a dispone la procedencia de abono de las costas con cargo al Tesoro público, de los sobreseidos y absueltos.

En Francia, «el condenado reconocido inocente...tiene derecho a reparación integral del perjuicio material y moral que le ha causado la condena» (art. 626 del Código de procedimiento penal - $\mathrm{CPP}-$ ). Igualmente por prisión provisional injustificada (art. $149 \mathrm{CPP}$ «...la persona que ha sido objeto de una detención provisional en el curso de un procedimiento finalizado respecto a él por una decisión de improcedencia, de puesta en libertad o de libre absolución, tiene derecho a reparación») y por error judicial particularmente en los supuestos de reconocimiento de inocencia tras la condena (art. $626 \mathrm{CPP})^{24}$.

\section{CONCLUSIONES DE LEGE DATA ET FERENDA}

Como colofón de este trabajo sobre la responsabilidad patrimonial directa del Estado Juez, por daños derivados del anormal funcionamiento de la Administración de Justicia y de los excepcionales supuestos causados por su funcionamiento normal (error judicial, prisión preventiva y recurso de revisión), lleva a las siguientes conclusiones:

1. En España aún no ha culminado el proceso de adaptación de la Administración de Justicia a los principios de la revolución liberal, del Estado social y democrático de Derecho y, en definitiva, de no se haberse consumado su evolución hasta considerar que el ciudadano, pues sigue sin considerar a la persona y a los derechos que le son inherentes el centro del orden político y del jurídico (art. $10 \mathrm{CE}$ ). Esta persistencia de la antigua divina maiestas de la monarquía absoluta, amparada entre otras cosas en su irresponsabilidad patrimonial por daños a las personas, tanto de iure cuanto más aún de facto, lleva a que se exacerbe el deber de obedecer a los Jueces y Tribunales consagrado en la CE (art. 118) en detrimento de los derechos de los ciudadanos (art. 24) que, ante la Administración de Justicia, se sienten con frecuencia más súbditos que ante las demás administraciones públicas.

23 Beling, E., Derecho procesal penal, Labor, Barcelona 1943, pp. 393-394. Roxin, C., Derecho procesal penal, Editores del Puerto, Buenos Aires 2000, pp. 511-514.

24 CANivet, G. y Jol Y-Hurard, J., «La responsabilité des juges, ici et ailleurs», Revue Internationale de Droit Comparé, 4-2006, pp. 1049-1.093.

UNED. Teoría y Realidad Constitucional, núm. 38, 2016, pp. 411-431 
2. Carecen de sentido los privilegios de la Administración de Justicia en este ámbito en comparación con las restantes administraciones públicas, pues debería responder igualmente por los daños derivados de su normal o anormal funcionamiento como las demás. Sin necesidad de reformar la Constitución —art. 121-, por tratarse de una ampliación de los derechos fundamentales del ciudadano a una tutela judicial efectiva, deberían modificarse en este sentido los actuales artículos 292 a 297 de la LOPJ, sin dar márgenes de interpretación restrictiva a los Tribunales, viciados de parcialidad en estos ámbitos.

3. También hay que censurar la interpretación restrictiva de las normas que regulan los supuestos en que procede el resarcimiento, por anormal funcionamiento de la Administración de Justicia, por error judicial y por prisión preventiva seguida de sobreseimiento o absolución por inexistencia del hecho. El anormal funcionamiento por su conformación desde la perspectiva de la «normalidad estadística», especialmente en relación con las dilaciones indebidas; el error judicial, por pervertir un supuesto resarcible del normal funcionamiento en una especie del funcionamiento anormal, cuando el artículo 121 de la CE lo considera un supuestos alternativo y distinto a tal supuestos. Y también hay que censurar la autoinmunidad que en ambos caso proporciona el procedimiento de exigencia de tal responsabilidad, al ser la Administración de Justicia — la Jurisdicción - juez y parte en su estimación.

4. Persiste un mal funcionamiento de la Administración Justicia por falta de medios personales y reales (particularmente de jueces, magistrados y fiscales titulares, y de eficaces oficinas judiciales con una red informática y una organización análoga a la de la Agencia Tributaria o la Seguridad Social), por inercias del Ancien Régime y por una hipertrofia de la litigiosidad debida en gran parte al excesivo número de abogados y al mantenimiento por los letrados de las administraciones públicas de pretensiones insostenibles ante la jurisdicción, particularmente como demandados. Pues bien, este mal funcionamiento sería remediado con más urgencia y eficacia, en lo atinente a los errores judiciales y el anormal funcionamiento de la administración de Justicia, si tuviera el erario público que indemnizarlos, gasto que se sumaría al silencioso que ya le genera el trabajo inútil vinculado a esos errores y anormales funcionamientos, y en lo relacionado con la querulancia y temeridad de los abogados, el remedio sería la implantación en la LECr el sistema de costas previstos en la LEC ${ }^{25}$; ambos remedios propiciarían además que los ciudadanos se vieran com-

25 Rodriguez Ramos, L., «'Malversaciones’ endémicas en la justicia penal. Necesaria 'civilización' de la condena en costas y de la responsabilidad patrimonial del Estado-Juez», Diario La Ley 24 de febrero de 2014. 
pensados por los daños y perjuicios que padecen como consecuencia de esa querulancia y mal funcionamiento de la Justicia.

$* * *$

TITLE: Appearance and Reality of the Patrimonial Responsibility of the Judicial Power (Limits of the Article 121 Spanish Constitution)

AвSTRACT: This paper analyses the patrimonial responsibility of the Judicial Power established in art. 121 Spanish Constitution. The paper describes the historical precedents of article 121 CE, the legislative development, the jurisprudential interpretation of it, which it could be considered unconstitutionally from the systematic perspective of the articles 17,24, 106.2 and 121 CE; finally, there are a comparative analysis with other European countries and some reform proposals.

RESUMEN: El presente trabajo analiza la responsabilidad patrimonial del Estado juez establecida en el art. 121 CE. En él se describen los precedentes históricos de este artículo 121 de la CE, su posterior desarrollo legislativo, la interpretación jurisprudencial de dichas normas, que se considera reductora y palmariamente inconstitucional desde la perspectiva sistemática del conjunto que forman los articulos 17, 24 y los citados 106.2 y 121 de la CE; finalmente se comparan estos elementos con los de otros estados europeos y se termina con concretas propuestas interpretativas y de lege ferenda.

KEY WORDS: Patrimonial responsibility of the State, Judicial Power.

Palabras clave: Responsabilidad patrimonial del Estado juez, Poder Judicial.

FeCHA DE RECEPCIÓN: 02.06.2016 FECHA DE ACEPTACIÓN: 27.07.2016 
